\title{
Topical mitomycin C effect on swine vocal folds healing
}

\section{Paulo Antônio Monteiro Camargo ${ }^{1}$, Antonio Carlos \\ Ligocki Campos ${ }^{2}$,Jorge Eduardo Fouto Matias ${ }^{3}$, Daniel Zeni Rispolí, Paulo Eduardo Przysiezny, Vinícius Ribas Fonseca ${ }^{6}$}

Keywords: Mitomycin, Wound Healing, Vocal Folds, Laser Surgery, Swines

\section{Summary}

\begin{abstract}
Several adjuvant therapies to surgery have been used to modulate the healing process of vocal folds, including topic mitomycin (MTC). Aim: to evaluate the effect of topical MTC in the healing process of vocal folds 30 days after the exeresis of a mucosal fragment with $\mathrm{CO}_{2}$ laser in a swine model (control group without mitomycin and study group with topical MTC), with collagen deposition measurement. Study type: prospective experimental in swine. Methods: two groups of 6 swine each were subjected to exeresis of a mucosal fragment of the vocal fold with $\mathrm{CO}_{2}$ laser. Immediately after the procedure MTC was applied topically for three minutes on the study group. Thirty days later the animals were slaughtered and samples of the vocal folds were collected for histological analysis, with the purpose of quantifying collagen deposition by Picrosirius Red stain. Results: the average area of total collagen in the vocal folds in the control group was $2.648,03 \mu \mathrm{m} 2$, whereas in the study group it was $2.200,30 \mu \mathrm{m} 2(\mathrm{p}=0.0043)$. Conclusion: topical application of MTC after the exeresis of a mucous fragment of vocal fold with $\mathrm{CO}_{2}$ laser in swine significantly decreased total collagen deposition.
\end{abstract}

${ }^{1}$ M.Sc in Surgery (Founder of the Otology and Laryngology Service at the Otorhinolaryngology Department at Angelina Caron Hospital) 2 Doctorate in Surgery (Professor at the Surgery Department)

3 Doctorate in Surgery (Assistant Professor at the Surgery Department at Ufpr)

4 Doctorate in Surgery (Mentor of the Pharyngostomatology and Rhinology Service at the Otorhinolaryngology Service at Angelina Caron Hospital)

5 M.Sc in Oro-Maxillofacial Surgery(Resident in Otorhinolaryngology at Angelina Caron Hospital)

${ }^{6}$ Preceptor of Otorhinolaryngology of the Angelina Caron Hospital

Otorhinolaryngology and Cervical-facial Surgery Service at Angelina Caron Hospital

Please send your mail to Dr. Paulo A. Monteiro Camargo, Rua 7 de Setembro 6700, Seminário, CEP-80240-001, Curitiba, Pr, Brasil. e-mail: cao.pr@terra.com.br Paper submitted to the ABORL-CCF SGP (Management Publications System) on January 1st, 2006 and accepted for publication on June 2nd, 2006. Cod. 1668. 


\section{INTRODUCTION}

Laryngology has made great progress with the development and the improvement of several larynx visualization techniques, especially with the surgical microscope, and more recently with video-endoscopy. Today, phonomicrosurgery has allowed surgeons to perform procedures aiming to improve vocal quality and increase recovery speed of the phonatory function ${ }^{1}$.

However, the unavoidable result of any surgical incision is the possibility of creating a scar, as a potential source of a problem for the speechsurgeon searching for vocal quality ${ }^{2}$.

Other therapies such as systemic or topical corticosteroids, cooling prior to the surgical procedure and fibrin glue, have been investigated in an attempt to help modulate the scarring process on the vocal fold, after the removal of its mucus cover ${ }^{3,4}$.

Among the several investigated methods to modulate the scarring process, topical Mitomycin-C has proven to be an antimetabolic agent which inhibits fibroblasts proliferation when applied topically, selectively inhibiting DNA and RNA synthesis and altering protein synthesis.

The aim of this study is to evaluate scarring in pig vocal folds, after the exeresis of the mucus fragment with $\mathrm{CO}_{2}$ laser with and without the use of topical Mitomycin$\mathrm{C}$, and analyzing post- surgery total collagen deposition, after 30 days.

\section{MATERIALS AND METHODS}

This prospective and experimental study was carried out at the Experimental Farm at Paraná Federal University (UFPR), located in Piraquara, state of Paraná. The study followed the Brazilian School on Animal Experimentation principles (COBEA, 1991)5, and the recommendations for slaughtering of experimental animals proposed by Close et al, (1997) ${ }^{6}$. The experiment was approved by the Institution Ethical Committee.

\section{Research Groups}

In this experiment we used twelve Larger White pigs ( 6 males and 6 females) original from the Paraná Federal University farm, with an average of 10.131 gra$\mathrm{ms}$ and ages ranging from 27 to 31 days. Two randomly separated groups were formed with 6 animals each. The groups were submitted to mucus exeresis on the free rim of the left vocal fold anterior portion with $\mathrm{CO}_{2}$ laser. The control group did not use any topical medication on the surgical area. On the other hand, topical Mitomycin-C was applied on the experimental group for three minutes, after exeresis.

\section{Surgical technique}

After anesthesia, the animals were placed on their backs, on a special table for castration covered with sterile surgical dressing. The top of the table was lifted and a cushion was placed on the upper dorsal region, to increase the angle and to facilitate larynx straightening. A Storz ${ }^{\circledR}$ children laryngoscope was used, with anterior commissure angle.

The vocal folds of the pigs were visualized with a D.F. Vasconcelosâ light microscope, straight binocular with $400 \mathrm{~mm}$ lens, and a Storz ${ }^{\circledR}$ coupled camera system. All surgical procedures were recorded in a VHS tape.

The surgical procedure started by holding the free rim of the left vocal fold anterior part, using Bouchayer Microfrance ${ }^{\circledR}$ tweezers ("heart" type). Then, using a 2 Watt $\mathrm{CO}_{2}$ Sharplan ${ }^{\circledR}$ laser, continuously and on the focused mode, on superpulse with $250 \mathrm{~m}$ microspot, the exeresis of the free rim fragment was done with 1 to $2 \mathrm{~mm}$, leaving a small surgical groove on the vocal fold free rim.

After the exeresis of the fragment, cotton soaked in MMC $(0.4 \mathrm{mg} / \mathrm{ml})$ was placed on the surgical wound during 3 minutes. Right after, the cotton was removed. MMC excess was removed using 0.9\% saline solution.

After anesthetic recovery, the pigs were put back in their pigsties, where they received water and food, 12 hours after surgery. Food supply was given twice a day, 24 hours after surgery.

\section{Microscopic analysis}

Thirty days after the surgical procedure, the 12 animals were submitted to the same pre-anesthetic and anesthetic procedures, followed by electrocution, according to what Close et al, (1997) ${ }^{6}$ proposed.

Their larynxes were removed in one piece, from the tongue to the fourth tracheal ring. An anterior longitudinal incision was made in the larynx, exposing the vocal folds, with incision of the thyroid cartilage, for the removal of all the vocal folds musculature, with the preservation of the mucus cover.

For the histological study, the Picrosirius Red solution with polarization was used. The non-collagen substance stained in black and the mature collagen in yellow, orange red and red (figures 1 and 2). For measuring the collagen deposition on the scarring process (fibroplasia) on the vocal folds mucosa surface, two histological measurements were taken in each stained sheet with Picrosirius Red after polarization.

After randomization was undone, the data was transferred to the Excel Windows ${ }^{\circledR}$ program, in order to obtain the arithmetic average. The statistical analysis was done next.

\section{Statistical analysis}

The unpaired comparisons were done using the Wilcoxon, non-parametric test, with the value $\mathrm{p} \leq 0.05$ being the statistical significance limit. 


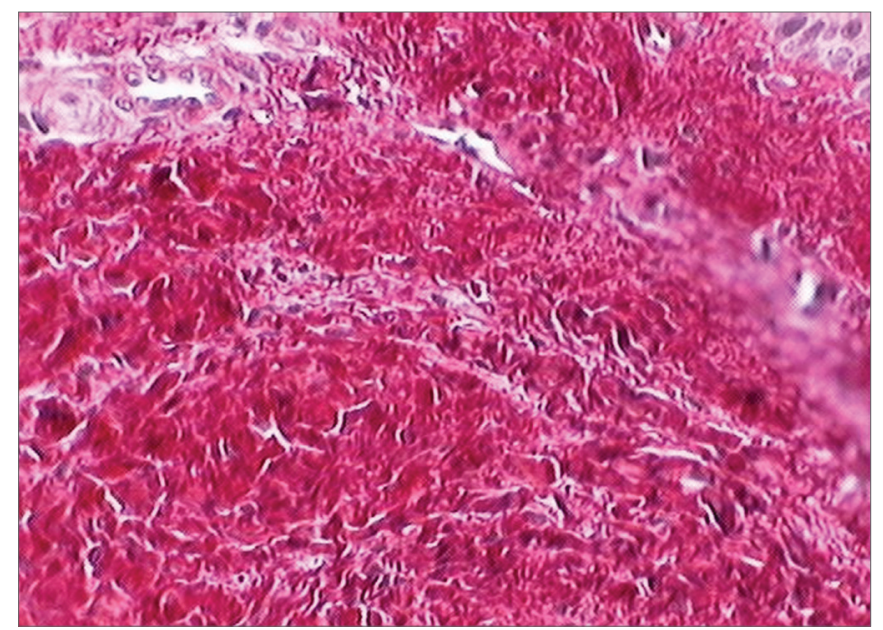

Figure 1. Vocal fold dyed by Sirius Red before polarization. This slide depicts the vocal fold submucosal region before polarization, and there is no distinction between cell elements and the connective tissue.

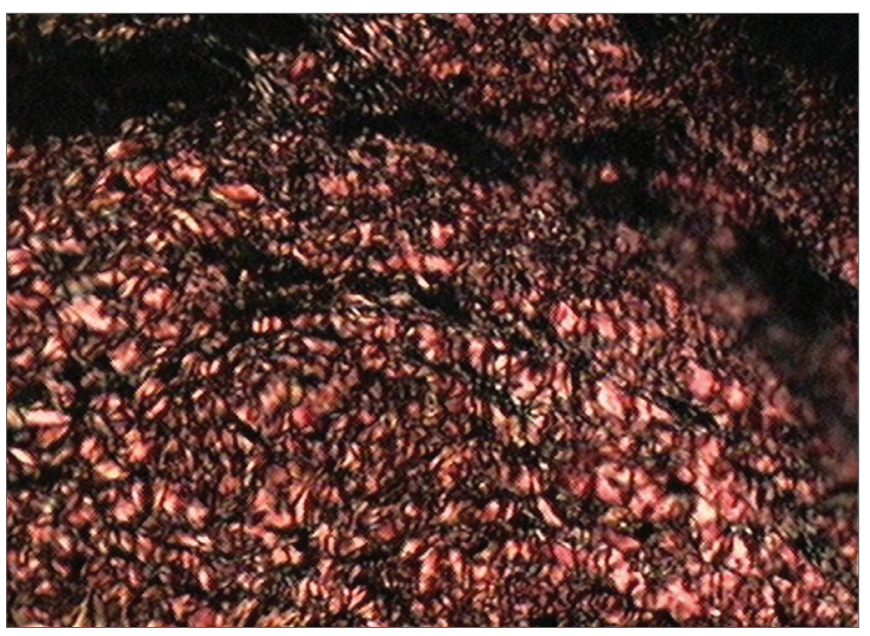

Figure 2. Vocal fold dyed by the Sirius Red solution after polarization. Notice the birefringent aspect: mature collagen with reddish orange dye and non-collagen substance dyed dark.

\section{RESULTS}

Macroscopically, all pigs had full vocal folds with physiological staining and without showing synechias after removal.

As for collagen deposition, the average collagen total area of the vocal folds in the group with exeresis of a fragment of the mucosa with laser without MMC, was of 2,648.93 $\mu \mathrm{m} 2$, whereas in the group with MMC it was of $2,200.30 \mu \mathrm{m} 2$.

In the comparison we made, the $\mathrm{p}$ value was of 0.0043 , showing statistical difference between the collagen quantity on the group submitted to a mucosa fragment exeresis in the vocal fold with laser, both treated and not treated with MMC (graph 1).

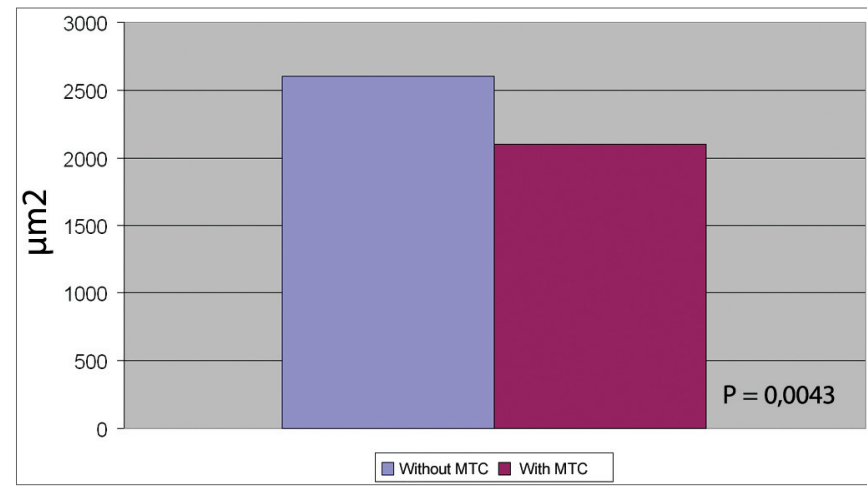

Graph 1 - Comparison of the total collagen average on CO2 laser partial exeresis, with and without mitomycin (MMC).

\section{DISCUSSION}

Even with the current techniques for mucosa and vocal ligament preservation, scars, fibrosis and consequently, stiffness are still a challenge for phonosurgeons ${ }^{1}$.

MMC is becoming more popular since several studies showed its efficacy in reducing post- operative fibrosis in supra glottic laryngeal stenosis ${ }^{7}$. Gray, Tritle $(2003)^{8}$, noted that MMC showed a greater effect in delaying scarring, when applied right before and after damaging the tissue, suggesting that there might be an adequate time interval between the lesion formation and the application time for obtaining the proper effect. Spector et al (1999)', showed significant reduction in granuloma formation and improvement in the crico-arythenoid mobility when using $\mathrm{CO}_{2}$ laser with topical MMC. Garrett et al (2001) showed that total collagen decrease was fixed with the use of topical MMC.

In the present study there was a statistically significant decrease of the total collagen with the use of MMC. These results suggest that the topical use of MMC when applied on the operated upon area, has an expressive effect in delaying the fibroplasia process, agreeing completely with Correa et al (1999) 10 results.

The choice of the surgical technique with $\mathrm{CO}_{2}$ laser, was based on Jako, Strong's studies (1972) ${ }^{11}$, who used it on the treatment of laryngeal papilomatosis and malignant lesions on initial stages. Currently, its indications have increased significantly with the technological evolution developed during the last years, such as the microspot decrease and the superpulse use, minimizing, as a consequence, the thermal damage on the surrounding tissues.

Santos et al (2003) $)^{12}$, compared incision on canine vocal folds made with cold instruments and with $\mathrm{CO}_{2}$ laser, assessing, through histological cuts, the quantity of fibroplasia. The results showed that collagen quantity on the vocal folds was greater on the group of animals submitted to lesions with cold instruments, than in those where $\mathrm{CO}_{2}$ laser was used. Therefore, $\mathrm{CO}_{2}$ laser is a safe 
method regarding collagen deposition, when compared to cold-bladed instruments, obviously when respecting the fundamental principles of phonomicrosurgery.

Sweat et al (1964) ${ }^{13}$, introduced in the histological technique the sirius red stain associated to the pricic acid (Picrosirius Red solution). Constantine, Mowry (1968) ${ }^{14}$, observed that the sirius red increase the birefringence of collagen fibers when studied on polarization microscope. In the current work Picrosirius Red solution was used associated with polarized microscopy, due to its great sensitivity and specificity. It is a simple and efficient method, because besides identifying the collagen fibers, it is capable of differentiating them into collagen types I, II and III through birefringence ${ }^{15-17}$.

Santos et al $(2003)^{10}$, evaluated the quantity of collagen deposition on canine vocal folds, through histological cross sections stained by the Picrosirius Red solution. They concluded that this solution, together with the polarization microscopy, is better able to depict collagen fibers.

In the present study, it was showed that the use of topical MMC, when applied on the operated upon area of vocal folds, is associated to a significant reduction in collagen deposition. Future studies, with more samples and with longer follow up time, will be necessary in order to confirm these results, and to define the ideal concentration and time for applying topical MMC.

\section{CONCLUSION}

Due to the results obtained with this experimental model in pigs, we can conclude that after 30 days of exeresis of a fragment of mucosa on the vocal folds, using $\mathrm{CO}_{2}$ laser, it was observed a decrease on collagen total area with the use of topical MMC applied right on top of the surgical wound, when compared to a exeresis without the use of topical MMC.

\section{REFERENCES}

1. Garrett CG, Soto J, Billante CR, Reinisch L. Effect of mitomycin-C on vocal fold healing in a canine model. Ann Otol Rhinol Laryngol 2001;110:25-30.

2. Eliashar R, Eliachar I, Esclamado R, Gramlich T, Strome M. Can topical mitomycin C prevent laryngotracheal stenosis? Laryngoscope 1999;109:1594-600.

3. Abitbol J. Atlas of Laser Voice Surgery. Singular. San Diego. 1995:121.

4. Bouchayer M, Cornut G. Microsurgery for benign lesions of the vocal folds. Ear Nose Throat J 1988;67:446-66.

5. C.O.B.E.A. (Colégio Brasileiro de Experimentação Animal) - Princípios éticos na experimentação animal. In: Congresso do Colégio Brasileiro de Experimentação Animal, São Paulo, 1991.

6. Close, B, Banister, K, Baumans, V, Bernoth, EM, Bromage, N, Bunyan, $\mathrm{J}$, et al. Recommendations for euthanasia of experimental animals: part two. Laboratory animals, 1997; 31:1-32.

7. Sennes LU, Tsuhji RK, Imamura R, Tsuhji, DH. O uso da mitomicina-C no tratamento endoscópico de estenoses supraglóticas. Arq Otorrinolaringol 2003;7:71-6.

8. Gray SD, Tritle N. The effect of mitomycin C on extracellular matrix proteins in a rat wound model. Laryngoscope 2003;113:237-42.

9. Spector JE, Werkhaven JA, Spector NC. Preservation of function and histological appearence of the injured glottis with topical mitomycinC. Laryngoscope 1999;109:1125-9.

10. Correa AJ, Reinisch L, Sanders DL. Inibition of subglottic stenosis with mitomycin-C in the canine model. Ann Otol Laryngol 1999;108:105360 .

11. Jako GJ, Strong MS. Laser surgery in the larynx: early clinical experience with continuous $\mathrm{CO} 2$ laser. Ann Otol Rhinol Laringol 1972;81:791-8.

12. Santos FCC, Grellet M, Aguilar Junior R, Jamur MC, Pinto JA, Fomin DS. Estudo comparativo histológico na prega vocal após incisão com instrumental a frio e com laser de $\mathrm{CO} 2 \mathrm{em}$ modelo animal. Rev Bras Otorrinolaringol 2003;69:753-9.

13. Sweat F, Puchtler H, Rosenthal SI. Sirius Red F3BA as strain for connective tissue. Arch Pathology 1964;78:69-72.

14. Constantine VS, Mowry RW. The selective staining of human dermal collagen II. The use of Picrosirius red F3Ba with polarization microscopy. J. Invest. Dermatol 1968;50:419-23.

15. Junqueira LCU, Cossermelli W, Brentani R. Differential staining of collagens type I, II and II by sirius red and polarization microscopy. Arch Histol Jap 1978;41:267-74.

16. Rabau MY, Dayan D. Polarization microscopy of picrosirius red stained sections: A useful method for qualitative evaluation of intestinal wall collagen. Hist Histopath 1994;9:525-8.

17. Szendrõi M, Vajta G, Kovács L, Schaff Z, Lapis K. Polarization colours of collagen fibres: a sign of collagen production activity in fibrotic process. Acta Morphol Hung 1984;32:47-55. 